\title{
MINICOMPOSTAGEM ECOLÓGICA: UMA ESTRATÉGIA DE EDUCAÇÃO AMBIENTAL EM ESCOLAS DE EDUCAÇÃO BÁSICA NO MUNICÍPIO DE LAGES/SC
}

Silvia Maria Alves de Oliveira ${ }^{1}$

Mariane Souza Melo de Liz²

Aline Nunes ${ }^{3}$

Lúcia Ceccato de Lima ${ }^{4}$

Ana Emilia Siegloch ${ }^{5}$

Resumo: O objetivo deste estudo foi avaliar o uso da Minicompostagem Ecológica (MCE) como estratégia contínua de Educação Ambiental nas escolas municipais e estaduais de educação básica de Lages/SC. O estudo mostrou que a prática da minicompostagem dos resíduos orgânicos no local onde foi gerado, apesar de ser um grande desafio para as escolas, tem sido uma importante estratégia para desenvolver uma educação ambiental continuada, sistematizada e multidisciplinar.

Palavras-chave: Resíduos Orgânicos; Educação Continuada; Destinação de Resíduos.

\footnotetext{
${ }^{1}$ Universidade do Planalto Catarinense. E-mail: olisilvia11@gmail.com.

2 Universidade do Estado de Santa Catarina. E-mail: mari-di-liz@hotmail.com.

3 Universidade do Estado de Santa Catarina. E-mail: alinenunes_bio@hotmail.com.

${ }^{4}$ Universidade do Planalto Catarinense. E-mail: ceccato@brturbo.com.br.

${ }^{5}$ Universidade do Planalto Catarinense. E-mail: asiegloch@gmail.com.
} 


\section{Introdução}

A Educação Ambiental (EA) é um tema não só em evidência, mas vital diante da mundialização que vivemos, porque as ações individuais e locais têm reflexo em toda a sociedade. Impulsionando e legitimando o crescimento econômico, a crise ambiental instalada na sociedade atual trouxe questionamentos sobre os fundamentos ideológicos e teóricos, ao perceber que a irracionalidade ecológica se tornou um padrão dominante de produção, consumo e descarte de resíduos (LEFF, 2006; MORIN, 2015).

A EA emerge e se funda em um saber que ultrapassa o conhecimento objetivo das ciências, remete à desconstrução do conhecimento disciplinar, simplificador e utilitário, buscando a construção e reconstrução de saberes a partir da interdisciplinaridade. Para Leff (2009), a EA apesar de toda a sua complexidade deve ser inserida dentro da cultura de um povo, propiciando a reflexão, construção e reconstrução de saberes.

Associados à solidariedade pela natureza e pela vida, à ética diante de outros seres e de posicionamentos políticos diante de ideologias ligadas ao meio ambiente, a EA busca a sustentabilidade e respeito pelo planeta. Ela fortalece a identidade do ser humano e reconhece o poder do saber, do pensar, do dialogar com o outro para atuar no mundo, fazendo renascer o pensamento utópico, o sentimento de liberdade e de ética para a construção de novas realidades (ROOS; BECKER, 2012). De acordo com Leff (2009, p. 18) "o saber ambiental integra o conhecimento racional e o conhecimento sensível, os saberes e os sabores da vida".

Em relação aos marcos históricos da Educação Ambiental no Brasil, em 1981 foi promulgada a Lei oㅡ 6.938 que dispõe sobre a Política Nacional do Meio Ambiente (PNMA), onde se reconheceu a necessidade de oferta da EA em todos os níveis de ensino, inclusive a educação da comunidade para instrumentalizá-la em defesa ativa do meio ambiente (BRASIL, 1981). O parecer 226 de 1987, aprovado pelo Ministério da Educação e Cultura (MEC) caracterizou a EA como interdisciplinar, marcando a posição do governo federal diante das discussões das secretarias estaduais e municipais de educação quanto à possibilidade desta se tornar disciplina específica (LOUREIRO, 2006).

Entre 1986 e 1990, o Programa das Nações Unidas para o Meio Ambiente (PNUMA) realizou o primeiro curso de especialização em Educação Ambiental no país. A EA foi incluída na Constituição Federal brasileira de 1988, tornando-se fundamental e obrigatória. No artigo 225 da Constituição, há menção ao meio ambiente e sua existência como um direito de todas as gerações, e um bem de uso comum (BRASIL, 1988).

Em 1996, o MEC disponibilizou os Parâmetros Curriculares Nacionais (PCN) que foram oficialmente lançados em 1997. Esse documento trouxe à discussão um volume dedicado aos temas transversais do currículo escolar, dentre eles, o meio ambiente e a saúde. Direcionado primeiramente aos docentes de $1^{\underline{a}}$ à $4^{\underline{a}}$ série do ensino fundamental, em 1998, foi ampliado de $5^{\underline{a}}$ à

Revbea, São Paulo, V. 14, № 2: 103-118, 2019. 
8 a série (CZAPSKI, 2008). O PCN tornou-se referência para orientar as instituições de ensino de todo país na tarefa de enfrentar antigos problemas educacionais e desafios colocados pelas novas características da sociedade (CZAPSKI, 2008).

Em 1999, foi instituída a Lei Federal no 9.795, sobre a Política Nacional de Educação Ambiental (PNEA), que definiu a EA como um processo pelo qual o indivíduo e a coletividade constroem valores sociais, conhecimentos, habilidades, atitudes e competências voltadas para a conservação e sustentabilidade do meio ambiente (BRASIL, 1999). A regulamentação desta lei ocorreu somente em junho de 2002 (Decreto Federal 4.281), e com isso criaram-se as condições necessárias para a implantação de fato da PNEA no Brasil (CZAPSKI, 2008).

No estado de Santa Catarina, os profissionais da educação foram articulados em grupos multidisciplinares para implementar a Proposta Curricular estadual, e a educação ambiental foi introduzida como um dos temas multidisciplinares a serem trabalhados no espaço escolar. Inserida no currículo escolar, através da EA objetivou-se um compromisso ético com a vida, alicerçado em duas dimensões principais: a primeira baseada no conhecimento científico e a segunda na possibilidade de ultrapassar limites, sejam estes individuais ou coletivos (SANTA CATARINA, 1998).

A escola desempenha papel fundamental na busca por um mundo mais sustentável, na formação de cidadãos sensíveis e responsáveis em relação às questões ambientais. No espaço escolar se reúnem os profissionais da educação, com objetivo de informar e formar indivíduos para viver em harmonia na sociedade (BRANCO, 2003). Assim, a intrínseca transversalidade e interdisciplinaridade da EA, são importantes instrumentos para a reflexão das pessoas no processo de mudança de atitudes em relação ao descarte ambientalmente adequado dos resíduos produzidos e à valorização do meio ambiente (GUSMÃO, 2000), o que constituiu um dos maiores desafios da gestão pública brasileira.

Os indivíduos devem adquirir na escola um repertório comum de interpretações e explicações, regras e procedimentos que podem ser aplicados à vida cotidiana, evoluindo em comportamentos, conjuntos de ideias ou concepções (BARCELLOS et al., 2005). Assim, perceber os problemas atuais do cotidiano e incluí-los no currículo escolar é um desafio constante. No entanto, é uma maneira profícua de tornar a educação significativa, efetiva e fundamental na mudança de paradigmas da sociedade perante problemas ambientais.

$\mathrm{Na}$ atualidade, muitos dos problemas ambientais poderiam ser minimizados ou até resolvidos se fossem realizadas mudanças no estilo de vida das pessoas. Uma mudança de concepção e comportamento deveria ser adotada perante a utilização dos recursos naturais e na forma como há o retorno destes materiais para o ambiente. Uma destas mudanças de paradigma é necessária perante o gerenciamento correto de resíduos.

revista brasileira educação ambiental 
A aprovação da Política Nacional de Resíduos Sólidos (PNRS) no Brasil em 2010, trouxe avanços significativos na implementação de políticas públicas que modificaram a relação dos indivíduos com a destinação dos resíduos produzidos, minimizando assim, os impactos ao meio ambiente (BRASIL, 2010). Entre os avanços da PNRS está o incentivo ao descarte dos resíduos orgânicos através da compostagem ecológica, dado que estes resíduos representam cerca de $50 \%$ do total produzido pelos municípios brasileiros.

No município de Lages, em Santa Catarina, no ano de 2012, foi implantado o projeto de extensão "Lixo Orgânico Zero" da Universidade Estadual de Santa Catarina (UDESC-CAV). O projeto foi uma parceria do Serviço Social do Comércio (SESC) em conjunto com o Centro de Educação Infantil (CEIM) Valéria Góss. Nesse projeto buscou-se a orientação para o ato de destinar de forma correta os resíduos orgânicos no espaço onde ele é gerado, aplicando a técnica de Minicompostagem Ecológica (MCE).

Em 2013, o projeto teve expansão a partir do Grupo de Apoio a Implantação do Plano de Resíduos Sólidos (GARIS) e do Centro de Ensino e Apoio a Pesquisa (CEAP), e foi desenvolvido em outras instituições escolares do município de Lages, através da adesão das equipes escolares. Estes grupos optaram por destinar os resíduos orgânicos oriundos das copas e cozinhas, para a transformação em matéria humificada e rica em nutrientes, no próprio espaço escolar.

Durante um período de cerca de 3 anos, este projeto foi executado cotidianamente nas escolas do município, com o auxílio de seus mentores e de voluntários. A presença de equipes auxiliando na sua implementação e o empenho da comunidade escolar foi indispensável para que a iniciativa se mantivesse em pleno funcionamento por longo período.

Partindo da premissa de que o Projeto Lixo Orgânico Zero teve uma boa adesão por parte da comunidade escolar lageana, o objetivo desta pesquisa foi avaliar o desenvolvimento da minicompostagem ecológica como estratégia continuada de Educação Ambiental nas escolas municipais e estaduais de educação básica de Lages. Além disso, investigou-se a inserção da prática da minicompostagem ecológica no Projeto Político Pedagógico (PPP) das escolas. Seus resultados visam fornecer as contribuições e as dificuldades para implantação de um projeto de longa duração, bem como a possibilidade de incentivar a técnica nas residências dos envolvidos no processo.

\section{Material e Métodos}

\section{Descrição da técnica de minicompostagem ecológica}

A técnica de minicompostagem ecológica implica na separação diária dos resíduos orgânicos dos demais resíduos produzidos. Tais resíduos orgânicos são dispostos em canteiros ou em vasos de forma organizada, em fileiras de 8 a $20 \mathrm{~cm}$ de altura, cobertos com grama, folhas, serragem, palha ou cinza de termoelétrica (GÜTTLER et al., 2014). Segundo os autores, nos 
primeiros dias é necessário o revolvimento para a entrada de oxigênio, evitando a infestação de insetos e possíveis odores desagradáveis.

Na MCE, o material orgânico (restos de alimentos, verduras, cascas de frutas, grama, folhas e podas) sofre decomposição/mineralização microbiológica. Após um tempo aproximado de 30 a 40 dias, é possível semear ou plantar sobre o composto formado, ou o adubo pode ser utilizado na fertilização de jardins e hortas da própria escola (GÜTTLER et al., 2014). Percebe-se que a técnica de MCE se diferencia de compostagens amplamente difundidas na literatura pela grande possibilidade de engajamento das pessoas que conseguem desenvolvê-la com facilidade no espaço próximo onde o resíduo orgânico é gerado.

O Projeto Lixo Orgânico Zero obteve recursos de um Termo de Ajustamento de Conduta do Ministério Público do Estado de Santa Catarina, o que possibilitou a aquisição de recursos materiais e recrutamento de profissionais para ampliar a sua implantação nas escolas. Este projeto contou com a adesão de 96 escolas, centros de educação infantil e centros de educação profissional de Lages, o que representa $62,74 \%$ do total de instituições de ensino existentes no município. Diversas atividades como visitas, encontros, palestras e oficinas foram realizadas para divulgar e orientar o processo da Minicompostagem Ecológica, com o intuito de sensibilizar os envolvidos a destinar os resíduos orgânicos nos espaços disponíveis nas escolas. O trabalho prático de construção de canteiros e manejo de pilhas de resíduos, bem como as visitas semanais para acompanhamento foram essenciais.

Diante deste panorama, sentiu-se a necessidade de realizar um levantamento e quantificação do sucesso real da implementação do projeto Lixo Orgânico Zero por um viés menos empirista e mais técnico, com intuito de verificar se a Minicompostagem Ecológica se tornara uma prática efetiva por parte dos agentes envolvidos no processo.

\section{Tipo de estudo e coleta dos dados}

Este estudo consistiu em uma pesquisa quantitativa do tipo exploratóriodescritiva, a partir do levantamento de informações sobre a utilização da prática da Minicompostagem Ecológica para o descarte de resíduos orgânicos nas escolas de Educação Básica da cidade de Lages, no estado de Santa Catarina. No município, há 33 escolas municipais e 25 estaduais de Educação Básica. Deste total, 41 escolas aderiram à prática da MCE em 2013. No entanto, apenas 17 continuavam com a prática até a realização da presente pesquisa (Figura 1).

A partir de informações obtidas junto a secretaria de educação do município e diretores das escolas, foram selecionadas as 17 escolas de Educação Básica, que desenvolveram de forma ininterrupta a prática da minicompostagem ecológica, entre 2013 e 2015, no espaço escolar. Estas escolas foram selecionadas segundo o critério de que seguiam com a prática 
da minicompostagem ecológica até o momento em que os questionários foram aplicados.

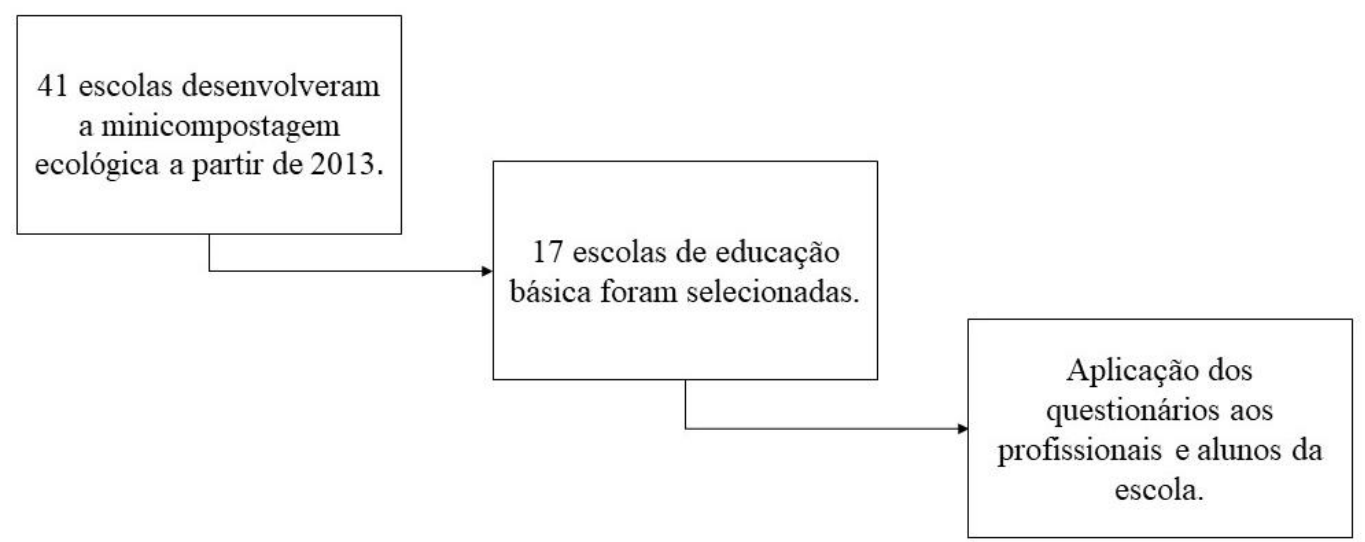

Figura 1: Fluxograma de triagem das instituições de ensino selecionadas para a aplicação da coleta de dados. Fonte: autoria própria.

A coleta de dados foi realizada entre julho e agosto de 2015, por meio de um questionário estruturado contendo questões fechadas e algumas abertas. Uma visita foi agendada em cada uma das escolas para apresentar esclarecimentos aos participantes sobre a pesquisa e demais informações do Termo de Consentimento Livre e Esclarecido (TCLE). Após consentimento, o questionário foi aplicado aos profissionais envolvidos com a prática da MCE (professores, merendeiras e auxiliares de serviços gerais) e aos estudantes.

O questionário aplicado aos profissionais da escola foi composto de duas partes. A primeira com questões fechadas e comuns para todos, sobre: (1) a função e tempo de trabalho na escola; (2) opiniões sobre a destinação dos resíduos orgânicos da escola; (3) grau de dificuldade em separar os resíduos gerados; (4) nível de envolvimento com a prática; (5) tempo utilizado para o trabalho; (6) quantidade de resíduos desviados do aterro sanitário; (7) a irradiação da prática para outras pessoas; e (8) os benefícios relevantes do desenvolvimento da MCE. A segunda parte do questionário, destinada apenas aos professores, abordou sobre o envolvimento dos alunos no processo e como a MCE foi incluída em suas práticas pedagógicas. Também foram questionados se tinham conhecimento da inclusão da MCE e de outros projetos de educação ambiental no Projeto Político Pedagógico (PPP), além de listar possíveis entraves para o desenvolvimento de projetos relativos à educação ambiental na instituição escolar.

Em cada escola, uma turma de alunos que participou das práticas da MCE foi indicada pelos professores para participar desta pesquisa. Posteriormente, realizou-se um sorteio para a inclusão de cinco estudantes de cada turma no estudo. Estes estudantes responderam questões sobre (1) compreensão acerca do conceito de MCE; (2) o desenvolvimento da prática em suas residências; (3) a irradiação da prática para outros indivíduos; (4) a Revbea, São Paulo, V. 14, № 2: 103-118, 2019. 
contribuição desta prática para a mudança de hábitos e atitudes sobre a destinação adequada dos resíduos sólidos; e (5) o conhecimento sobre a relação entre destino de resíduos orgânicos e saúde.

Após a categorização e organização dos dados em planilhas, foram realizadas análises descritivas para a distribuição das frequências absolutas e percentuais.

Este estudo teve aprovação do Comitê de Ética em Pesquisa com Seres Humanos - CEP da Uniplac através do protocolo no 1.121.939/2015.

\section{Resultados e Discussão}

\section{Participação dos profissionais da escola}

Participaram deste estudo, 44 profissionais das 17 escolas de educação básica, sendo o grupo composto por 17 merendeiras, 11 auxiliares de serviços gerais e 16 educadores. A amostra foi caracterizada por $22,7 \%$ dos entrevistados do sexo masculino e $77,3 \%$ do sexo feminino. O tempo médio de serviço entre os profissionais na mesma escola foi de 7,2 anos.

Em relação à escolaridade dos participantes, $34,9 \%$ possuíam pósgraduação, $7,0 \%$ somente o nível superior, 34,9\% contavam com o ensino médio completo, 20,9\% possuía apenas ensino fundamental completo e 2,3\% dos indivíduos entrevistados não era completamente alfabetizado.

Quanto ao desenvolvimento da prática da MCE, $88,6 \%$ dos profissionais entrevistados relataram que os resíduos orgânicos produzidos na escola foram separados dos demais e enviados para a MCE. Houve relatos de que os resíduos orgânicos produzidos foram destinados para alimentação de animais $(2,3 \%)$, para a coleta pública $(2,3 \%)$, ou que apenas parte dos resíduos foi destinada para a MCE e outra parte à coleta pública (6,8\%). Alguns entrevistados descreveram ter entregue os resíduos para uma pessoa da comunidade do entorno que realizava a MCE em sua casa.

Este resultado demonstra que após três anos de aplicação do projeto, o hábito de separação dos resíduos orgânicos tornou-se muito comum nas escolas. Tal evidência é corroborada pelo trabalho de Santos et al., (2014), onde os autores afirmam que a utilização da compostagem em escolas apresenta grande eficiência em sua implantação, principalmente quando existe engajamento de todos os colaboradores.

Em torno de $29 \mathrm{~kg} / \mathrm{semanais}$ de resíduos orgânicos foram produzidos por cada escola. Destes, em torno de $25 \mathrm{~kg}$ (86\%) deixaram de ser encaminhados ao aterro sanitário de Lages. Desta forma, os resíduos orgânicos vêm sendo destinados de maneira mais adequada e retirados da coleta pública e do envio ao aterro sanitário municipal (GÜTTLER et al., 2014).

O desenvolvimento da prática da minicompostagem ecológica como alternativa para a destinação de resíduos orgânicos pode ser uma forma de implementar soluções viáveis para minimizar problemas ambientais que

revista brasileira educação ambiental 
atingem a população local. Muitos estudos têm evidenciado os diversos benefícios ambientais, sociais e econômicos da compostagem doméstica (ADHIKARI et al., 2010; COLÓN et al., 2010). No entanto, poucos são os projetos mantidos de forma continuada nas escolas e instituições brasileiras.

Quanto ao tempo utilizado diariamente na destinação dos resíduos orgânicos para a MCE, $26,2 \%$ dos entrevistados afirmaram gastar apenas 5 minutos nestas tarefas específicas, 21,4\% responderam que despendem de 6 a 10 minutos na destinação, 33,3\% dos entrevistados afirmam que gastam de 11 a 20 minutos nas tarefas da MCE, $14,3 \%$ gastam de 21 a 30 minutos diariamente, e por fim, 4,8\% afirmaram levar mais de 31 minutos para executar as atividades. Estes resultados bastante variáveis, podem estar relacionados ao tamanho distinto entre as escolas, diferente número de alunos que fazem refeições, número de refeições ofertadas pela escola e, pela quantidade de resíduos que precisam ser encaminhados à MCE diariamente.

Associado ao resultado anterior, foi contabilizada também a frequência com que os resíduos orgânicos foram encaminhados à MCE. Neste caso, $53,5 \%$ dos entrevistados responderam que os resíduos gerados foram encaminhados uma vez ao dia, 20,9\% encaminharam mais de uma vez ao dia, devido à maior quantidade de resíduos gerados; $18,6 \%$ afirmaram que os resíduos eram encaminhados à MCE 3 vezes na semana, e 7\% encaminharam apenas 2 vezes na semana.

De modo geral, $95 \%$ dos participantes acreditam que a disposição correta dos resíduos orgânicos deveria ser realizada através da separação e condução para MCE e os demais consideram importante aliar à alimentação de animais.

Com relação ao grau de dificuldade: $77,3 \%$ dos entrevistados responderam que não há dificuldade em separar e destinar os resíduos orgânicos no espaço onde ele foi gerado, 20,5\% considera que a dificuldade é média e apenas um indivíduo $(2,3 \%)$ considerou que o processo é difícil de realizar. Além disso, a maioria dos entrevistados diz sentir-se satisfeitos $(97,7 \%)$ em destinar os resíduos orgânicos para a MCE. Isto é indicado por Santos et al. (2014), onde afirmam que ambientes de hortas e composteiras, que são diferenciados das salas de aulas, proporcionam maior entusiasmo e motivação quando implementados no ambiente escolar.

Ainda sob o ponto de vista destes profissionais, as principais dificuldades levantadas para a destinação dos resíduos orgânicos para a MCE nas escolas, foram associadas à aquisição de material para cobrir os resíduos $(37,2 \%)$, à manutenção dos espaços limpos e organizados $(16,3 \%)$ e ao pouco envolvimento dos estudantes na atividade prática (14\%) (Figura 2). 


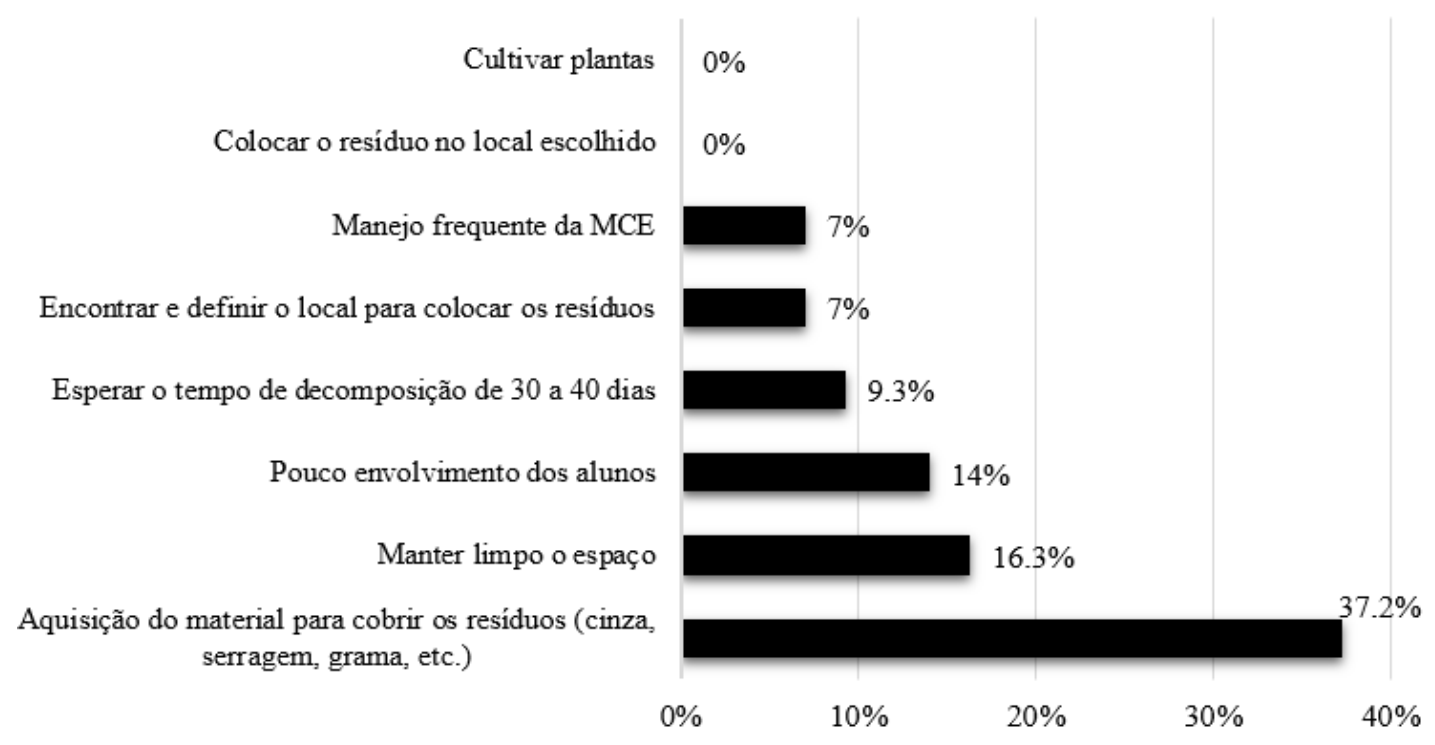

Figura 2: Principais dificuldades encontradas no processo de MCE na escola sob o ponto de vista dos professores, merendeiras e profissionais de serviços gerais. Fonte: autoria própria.

Em relação à irradiação do conhecimento atrelado ao desenvolvimento da prática da MCE, os dados revelam que $61,4 \%$ dos profissionais realizaram a separação do resíduo orgânico dos demais resíduos em suas residências, e desenvolveram a MCE em ambientes além da escola. Outros 31,8\% não realizaram a MCE em casa, e 6,8\% dos participantes desistiram da prática devido à falta de tempo e ao pequeno volume de resíduos orgânicos produzidos, porém, desenvolveram a prática por um período médio de 13 meses antes da desistência.

Constatou-se que $81,1 \%$ dos entrevistados acreditam que a destinação dos resíduos orgânicos para a MCE, pode ser expandida para as residências da comunidade. Em média cada entrevistado repassou a técnica da MCE para 68 pessoas, multiplicando as ideias que permeiam a minicompostagem ecológica e favorecendo a sua disseminação.

Este estudo mostrou ainda que os participantes reconhecem a prática da MCE como uma ferramenta para diminuição da poluição do meio ambiente $(41,9 \%)$, bem como, auxilia na conscientização ambiental da sociedade $(30,2 \%)$, gera um aumento da autoestima das pessoas que percebem a capacidade de solucionar um problema ambiental $(23,3 \%)$, possibilita ampliar a reciclagem $(2,3 \%)$ e aumenta o tempo de vida útil do aterro sanitário da região $(2,3 \%)$. Os participantes desta pesquisa demonstram comportamento semelhante ao relatado no estudo de Carvalho e Lima (2010), onde a vertente cívica é estimulada tanto nos estudantes quanto nos profissionais, visto que é sua responsabilidade e estritamente dependente de seu desempenho, fazer com que exista sucesso na atividade da compostagem escolar.

revista brasileira educação ambiental 


\section{$O$ relato dos professores sobre a $M C E$}

A equipe docente foi questionada em relação ao envolvimento dos estudantes nas práticas de destinação de resíduos orgânicos na escola, e $87,5 \%$ dos entrevistados afirmaram que os estudantes participaram efetivamente do desenvolvimento das práticas de MCE no espaço escolar. Também aos alunos foram ministradas aulas teóricas, por meio de discussões de textos, exercícios e tarefas de casa direcionadas ao tema da compostagem.

O tema do projeto foi abordado em diferentes disciplinas, oportunizando reflexões, debates e práticas que ampliaram o aprendizado dos estudantes em relação ao descarte adequado dos resíduos orgânicos. Promoveu-se maior capacidade de percepção, senso de pertencimento e corresponsabilidade em relação aos problemas de gestão dos resíduos do município, quebrando paradigmas consolidados quanto à destinação dos resíduos domésticos. A destinação de compostos orgânicos nas minicomposteiras, pode ser encarada como uma aula prática que oferece ao educador a possibilidade de trabalhar em um laboratório vivo e dinâmico (GALIAZZI; GONÇALVES, 2004).

Das 17 escolas envolvidas no estudo, $50 \%$ contemplaram a proposta do Projeto Lixo Orgânico Zero nos seus Projetos Políticos Pedagógicos (PPP) e destacaram que outros projetos de Educação Ambiental foram desenvolvidos concomitantemente, tais como: meio ambiente e jardinagem; sustentabilidade; paisagismo e conservação do patrimônio escolar; reciclagem; escola verde; plantio de árvores nativas, entre outros.

De acordo com Guimarães et al. (2012), os projetos de educação ambiental no espaço escolar ainda são desenvolvidos de maneira isolada, com pouca sistematização e participação de professores, resultado da falta de apoio da direção ou dos setores pedagógicos, e da ausência de recursos materiais e humanos. Isto remete a necessidade de a escola elaborar um planejamento mais cooperativo e organizado para permitir um trabalho interdisciplinar e exequível. Sua efetiva atuação é possibilitada através de ações de EA inseridas no PPP, como foi o caso da referida pesquisa. Quando um projeto não está inserido dentro do projeto pedagógico, ele permanece invisível, e assim, perde sua função dinamizadora do currículo tradicional (MELLO FILHO, 2014).

Dentre as dificuldades para desenvolver os projetos de EA na escola, $37,5 \%$ dos professores consideram que ser responsabilidade de todos é a principal dificuldade, assim como outros $37,5 \%$ consideram um empecilho a falta de carga horária destinada exclusivamente para o desenvolvimento de projetos. Ainda, $6,3 \%$ mencionam a falta de uma disciplina de educação ambiental e, o mesmo percentual $(6,3 \%)$ citaram a falta de motivação dos gestores. Apenas $12,5 \%$ não encontram entraves na aplicação de projetos de EA na escola (Figura 3). 


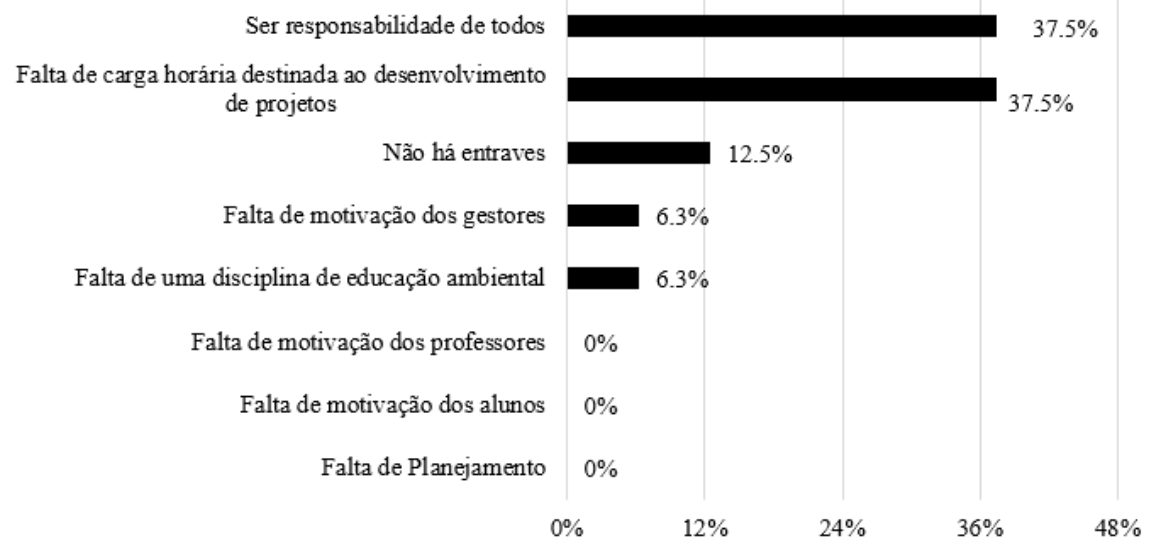

Figura 3: Dificuldades para o desenvolvimento da MCE na escola. Fonte: autoria própria.

Segundo Mello Filho (2014), mesmo que a compostagem seja um processo mais dinâmico e que modifica a rotina escolar, ainda assim é necessário que um servidor seja identificado como responsável pelo projeto para que ele não seja abandonado. Além disso, o autor evidencia que da forma como a carga horária dos professores está distribuída atualmente, é muito difícil que eles consigam desenvolver projetos ou temas transversais de EA na escola sem sobrecarga de trabalho.

Os professores também costumam relatar que existe certa insegurança ao tratar de um conhecimento que eles não possuíam de forma aprofundada, ou que não constava dentro da ementa dos conteúdos obrigatórios do currículo. Este fator torna o projeto uma atividade a mais em sua rotina, não sendo visto como complementar (MELLO FILHO, 2014). É perceptível que o desenvolvimento prático deste tipo de projeto ainda sofre com alguns entraves.

Apesar de algumas dificuldades apontadas, um alto percentual de entrevistados encaminhou os resíduos orgânicos gerados na escola para a MCE, bem como levou esta prática para suas residências e orientou outras pessoas para destinar os resíduos orgânicos domésticos no espaço onde foi gerado. Esse resultado está associado ao compromisso e motivação das pessoas em fazer o que lhes parece mais correto para a destinação dos resíduos produzidos no ambiente escolar.

\section{Participação dos estudantes nas práticas da MCE}

Dos 85 estudantes selecionados para o estudo, $84 \%$ responderam que foram informados sobre a destinação dos resíduos orgânicos para a MCE através do projeto Lixo Orgânico Zero, cuja temática havia sido abordada nas disciplinas de ciências, biologia, geografia, matemática, física e educação física. De acordo com Santos et al. (2014), percebe-se que a adoção de projetos de educação ambiental é quase sempre bem recebida pelos estudantes, demonstrado tanto no aspecto pedagógico quanto social, e que 
existe uma grande mobilização por parte destes quando a rotina é modificada. Toda a comunidade escolar pode se beneficiar deste tipo de atividade, sendo os alunos, o reflexo de um ensino-aprendizagem ativo.

Dentre os estudantes entrevistados, constatou-se que $40,3 \%$ realizaram efetivamente a MCE em suas residências, por 15 meses, e 17,7\% iniciaram o processo, mas desistiram da prática após 4,8 meses. A desistência da prática foi associada à falta de tempo (54,5\%), por não possuírem material para cobrir os resíduos orgânicos $(27,3 \%)$, falta de espaço apropriado, entre outros motivos (18,2\%). Para Bizerril e Faria (2001), a desistência de projetos de educação ambiental, por parte dos estudantes, é comum. Segundo os autores, mesmo projetos considerados de sucesso, podem sofrer com problemas, por falta de reforço ou repetição do funcionamento do projeto; pelas mudanças que um projeto pode sofrer ao longo do tempo; ou mesmo pela saída de pessoas que auxiliavam na sua implantação.

Os estudantes ensinaram a prática da MCE para uma média de três pessoas, o que permite deduzir que todas as pessoas do seu círculo familiar estiveram em contato, mesmo que incipiente, com a ideia da minicompostagem. Cerca de $92 \%$ dos estudantes acreditam que o destino correto dos resíduos orgânicos foi o envio para a MCE.

Em relação ao grau de dificuldade, os estudantes envolvidos na prática da MCE, avaliaram o processo como de nível fácil a médio; e cerca de 50\% dos entrevistados afirmaram que a família deu apoio para a execução da prática. Segundo os estudantes, as principais contribuições desta atividade foram: diminuição da poluição ambiental (50\%) e conscientização ambiental da sociedade $(32,3 \%)$.

A maior parte dos estudantes (83,9\%) pontuou que a escola tem contribuído para a sua mudança de hábitos e atitudes em relação à destinação dos resíduos produzidos. Destes, $75,8 \%$ responderam que acreditam que ações de EA continuadas como a MCE, a partir do projeto "Lixo Orgânico Zero" implantado nas escolas para a destinação adequada dos resíduos orgânicos, pode inclusive melhorar a sua saúde.

Para Abreu et al. (2011), os resultados de atividades que envolvem a prática em composteiras, hortas e parques, vão muito além do quantitativo, e demonstram que existem infinitas possibilidades de experiências que podem ser compartilhadas entre os alunos, professores, e servidores das escolas. $O$ espaço além da sala de aula é didático, promove integração social, desperta a educação ecológica e pode reduzir o estresse, aliado ao aumento da qualidade de vida, devido à quebra da rotina escolar comum (ABREU et al., 2011).

Projetos de educação ambiental contínuos, como o "Lixo Orgânico Zero", que buscam o envolvimento de vários atores escolares, têm demonstrado que o descarte ambientalmente adequado dos resíduos orgânicos domésticos no espaço onde é gerado, desenvolve-se de forma eficiente; além de mudar os hábitos e atitudes da comunidade escolar e da sociedade para resolver problemas de gestão dos resíduos.

Revbea, São Paulo, V. 14, № 2: 103-118, 2019. 
É importante mencionar que a receptividade dos funcionários das escolas, seus gestores e professores é um diferencial para que projetos ambientais tenham êxito. Estudos demonstram que o apoio fornecido pelos gestores escolares em atividades de mobilização, coordenação, planejamento, e motivação são essenciais em todos os processos de implementação de projetos de educação ambiental (SANTOS et al., 2017).

\section{Conclusões}

A implantação do Projeto "Lixo Orgânico Zero" no município de Lages, pode ser considerada uma ação bem-sucedida quando se analisam os dados coletados neste estudo. Mais de $80 \%$ dos resíduos das escolas foram corretamente destinados para a minicompostagem ecológica, o que implica em uma redução nos volumes conduzidos ao aterro municipal.

A forma com que o projeto foi concebido também deve ser destacado. Sua implantação é simples, e requer um tempo muito pequeno de dedicação à sua execução quando comparado aos outros trabalhos da rotina escolar. Portanto, sua efetivação esbarra apenas na complexidade atrelada à mudança de hábitos que este projeto requer de seus colaboradores. Além disso, 0 acompanhamento quase exaustivo do projeto, através de visitas periódicas e palestras de orientação foram extremamente importantes para que o processo de minicompostagem se tornasse hábito natural.

Os professores relataram neste estudo, que o processo de implantação do projeto foi relevante e entusiasmante para toda a comunidade escolar. A rotina foi modificada, o que aumentou a participação dos estudantes. $O$ aumento da autoestima de todos aqueles que participaram também é fato relevante, pois, motivação pessoal é algo que mantém projetos ativos por longos períodos.

Percebe-se que a existência de uma agenda especificamente voltada para a educação ambiental, com suporte de todos os gestores, diretores, mesmo das gerências de ensino é fundamental para que os profissionais da escola deem continuidade à educação ambiental. Isto acaba formando um ciclo, no qual professores motivados criam alunos motivados, que influenciam suas famílias e podem dar início a uma nova perspectiva de colaboração para a melhoria da disposição de resíduos ou a qualquer outro projeto de cunho ambiental.

A abordagem interdisciplinar intrínseca da educação ambiental e dos problemas socioambientais - o que inclui o gerenciamento dos resíduos sólidos -, permite que o aluno entenda o contexto amplo que permeia as relações que existem entre o homem e a natureza. Ele consegue perceber que se os problemas são socialmente construídos, também podem ser desconstruídos por meio de uma visão holística, que deve ser introduzida já no ambiente escolar. 


\section{Agradecimentos}

Ao Fundo de Apoio à Manutenção e ao Desenvolvimento da Educação Superior (FUMDES), através do Programa de Bolsas Universitárias de Santa Catarina UNIEDU.

\section{Referências}

ABREU, M. J.; CORDEIRO, A. F.; FARIAS, E.; MAESTRI, J. C.; MELO, L. S. Horta escolar e agroecologia em 43 unidades educativas de Florianópolis. In: Resumos do VII Congresso Brasileiro de Agroecologia - Fortaleza/CE - 12 a 16/12/2011. Cadernos de Agroecologia, Rio de Janeiro, v. 6, n. 2, dez. 2011.

ADHIKARI, B.; TRÉMIER A.; MARTINEZ, J.; BARRINGTON. S. Home and community composting for onsite treatment of urban organic waste: perspective for Europe and Canada. Waste Management \& Research, Toronto, v.28, n. 11, p. 1039 - 1053, nov. 2010.

BARCELLOS, P. A.; AZEVEDO JUNIOR, S. M.; DE MUSIS, C. R.; BASTOS, H. F. B. N. As representações sociais dos professores e Alunos da escola municipal Karla Patrícia, Recife, Pernambuco, sobre o manguezal. Ciência \& Educação, Bauru, v. 11, n. 2, p. 213-222, 2005.

BIZERRIL, M. X. A.; FARIA, D. S. Percepção de professores sobre a educação ambiental no ensino fundamental. Revista Brasileira de Estudos Pedagógicos, Brasília, v. 82, n. 200/201/202, p. 57-69, jan. /dez. 2001.

BRANCO, S. Educação Ambiental: metodologia e prática de ensino. 1. ed. Rio de Janeiro: Dunya, 2003.

BRASIL. Constituição da República Federativa do Brasil de 1988. Brasília, 1988. Disponível em: <http://www.planalto.gov.br/ccivil 03/constituicao/ ConstituicaoCompilado.htm>. Acesso em: 02 fev. 2018.

BRASIL. Lei no 6938 de 31 de agosto de 1981. Institui a Política Nacional do Meio Ambiente, seus fins e mecanismos de formulação e aplicação, e dá outras providências. Diário Oficial da União. Brasília, 1981. Disponível em: $\leq$ http://www.planalto.gov.br/ccivil 03/leis/L6938.htm>. Acesso em: 10 fev. 2018.

BRASIL. Lei no 9795 de 27 de abril de 1999. Dispõe sobre a educação ambiental, institui a Política Nacional de Educação Ambiental e dá outras providências. Diário Oficial da União. Poder executivo, Brasília, DF. 29 abr. 1999. Disponível em: <http://www.mma.gov.br/port/conama/legiabre.cfm? codlegi=321>. Acesso em: $21 \mathrm{fev} .2018$

BRASIL. Lei no12.305 de 2 de agosto de 2010. Institui a Política Nacional de Resíduos Sólidos; altera a Lei no 9.605, de 12 de fevereiro de 1998; e dá outras providências. Disponível em: shttp://www.planalto.gov.br/ccivil 03/ ato2007-2010/2010/lei//12305.htm >. Acesso em: 24 abr. 2018. 
CARVALHO, S.; LIMA, N. Compostagem doméstica em Educação Ambiental: potencial de uma abordagem holística. CAPTAR: ciência e ambiente para todos, Portugal, v. 2, n. 2, p. 40-54, 2010.

COLÓN, J.; MARTÍNEZBLANCO, J.; GABARRELL, X.; ARTOLA, A.; SÁNCHEZ, A.; RIERADEVALL, J.; FONT, X. Environmental assessment of home composting. Resources, Conservation and Recycling, v. 54, n. 11, p. 893-904, set. 2010.

CZAPSKI, S. Os diferentes matizes da educação ambiental no Brasil: 1997-2007. Brasília, Editora: MMA (Ministério do Meio Ambiente), 2008.

GALIAZZI, M. C.; GONÇALVES, F. P. A natureza pedagógica da experimentação: uma pesquisa na licenciatura em química. Química Nova, São Paulo, v. 27, n. 2, p. 326-331, mar. /abr. 2004.

GUIMARÃES, Z. F. S.; SANTOS, W. L.P; MACHADO, P. F. L.; BAPTISTA, J.A. Projetos de educação ambiental em escolas: a necessidade da sistematização para superar a informalidade e o improviso. Pesquisa em Educação Ambiental, São Paulo, v. 7, n. 1, p. 67-84, 2012.

GUSMÃO, O. S.; SETÚBAL, F. A. R.; NOVAES, A. B. C.; DIAS, S. M. F. Reciclagem artesanal na UEFS: estratégia educacional na valorização do meio ambiente. In: Congresso Nacional de Meio Ambiente na Bahia, 2. Anais. Salvador: UFBA, p. 56-58, 2000.

GÜTTLER, G. TAFFAREL, A. NASCIMENTO, B. MARCO, E. RIBEIRO, J.A. JESUS, J.R. GÖDE, J.N. OLIVEIRA, S. MILANI, V. Projeto Lixo Orgânico Zero em Lages-SC. In. Seminário de Extensão Universitária da Região Sul (SEURS), 32, Curitiba, 18 a 22 de agosto, 2014, Anais. Universidade Federal do Paraná, 2014. Disponível em: <www.proec.ufpr.br/seurs> Acesso em: 19 mai. 2018.

LEFF, E. Complexidade, racionalidade ambiental e diálogo de saberes. Educação e Realidade. Rio Grande do Sul, v. 34, n. 3, p.17 a 24, set/dez. 2009.

LEFF, E. Racionalidade Ambiental: a reapropriação social da natureza. 2. ed. Rio de Janeiro: Civilização Brasileira, 2006.

LOUREIRO, C. F. B. Trajetória e fundamentos da educação ambiental. 2. ed. São Paulo: Cortez, 2006.

MELLO FILHO, N. R. Aplicação e avaliação de técnicas de agroecologia e compostagem como dinamizadores da educação ambiental nos currículos e espaços escolares. 2014, 183. Dissertação (Mestrado em Ciência e Tecnologia Ambiental). Universidade Tecnológica Federal do Paraná, Curitiba, 26 ago. 2014.

MORIN, E. A via para o futuro da humanidade. 2. ed. Tradução: Edgard de Assis Carvalho e Mariza Perassi Bosco. Rio de Janeiro: Bertrand Brasil, 2015. 
ROOS, A.; BECKER, E. L. S. Educação ambiental e sustentabilidade. Revista Eletrônica em Gestão, Educação e Tecnologia Ambiental: REGET/UFSM. V .5, n5, p. 857 - 866, 2012.

SANTA CATARINA. Governo do Estado. Secretaria de Estado da Educação. Proposta Curricular de Santa Catarina: formação integral na educação básica. 2014. Disponível em: < http://www.propostacurricular.sed.sc.gov.br /site/Proposta Curricular final.pdf >. Acesso em: 10 mai. 2018.

SANTA CATARINA. Secretaria de Estado da Educação e do Desporto. Proposta Curricular de Santa Catarina: Educação Infantil, Ensino Fundamental e Médio: Temas Multidisciplinares. Florianópolis: COGEN, 1998. Disponível em: <http://www.propostacurricular.sed.sc.gov.br/pdfs /PC Temas Multidisciplinares.pdf>. Acesso em: 10 mai. 2018.

SANTOS, A. M. L.; MARTINS, R. M. L.; SOUZA, R. D.; MOTA, R. M. F.; FERNANDES, C. T. Incentivo ao Uso da Compostagem de Resíduos Sólidos em uma Horta Escolar do Município de Jaciara-MT. Unopar Científica: Ciências Humanas e Educação, Londrina, v. 15, p. 321-329, dez. 2014.

SANTOS, C. R.; GRILLI, N. M.; GHILARDI-LOPES, N. O.; TURRA, A. A collaborative work process for the development of coastal environmental education activities in a public school in Sao Sebastião (Sao Paulo State, Brazil). Ocean \& Coastal Management, p. 1-9, 2017. 